\title{
Videogames: Dispelling myths and tabloid headlines that videogames are bad
}

\author{
Christian M Jones \\ University of the \\ Sunshine Coast \\ Queensland, Australia \\ cmjones@usc.edu.au
}

\author{
Laura Scholes \\ University of the \\ Sunshine Coast \\ Queensland, Australia \\ I.scholes@usc.edu.au
}

\author{
Daniel Johnson \\ Queensland University \\ of Technology \\ Queensland, Australia \\ dm.johnson@qut.edu.au
}

\author{
Mary Katsikitis \\ University of the \\ Sunshine Coast \\ Queensland, Australia \\ mkatsiki@usc.edu.au
}

\author{
Michelle C. Carras \\ Johns Hopkins \\ University \\ Baltimore, MD, USA \\ mcarras@jhsph.edu
}

\begin{abstract}
Videogamers are often portrayed as adolescent overweight males eating fast food in their bedroom, and videogames often blamed in the media for violent crime, obesity, social isolation and depression. However videogaming is a mainstream activity. In Australia $65 \%$ of the population play videogames (Digital Australia 2014), and humanity as a species play about 3 billion hours of videogames a week. This paper dispels the myths and sensationalised negative tabloid headlines that videogames are bad by presenting the latest research showing that videogames can help fight depression, improve brain function and stimulate creativity; that gamers have higher levels of family closeness and better attachment to school; and that videogames help boys and young men to relax, cope and socialise. Children and adolescents deliberately choose to play videogames in the knowledge that they will feel better as a result, and videogame play allow players to express themselves in ways they may not feel comfortable doing in real life because of their appearance, gender, sexuality, and/or age. The potential benefits of videogames to the individual and to society are yet to be fully realised. However already videogames are helping many gamers to flourish in life.
\end{abstract}

Videogames, violence, obesity, social, depression, flourishing, wellbeing, mental health.

\section{INTRODUCTION}

Videogames have been blamed for many of the problems faced by society. Problems from obesity to obsession, and from depression to violence. The 'media' (TV and newspapers) have reported videogames as glorifying violence, and videogame players as smelly, overweight, acne-ridden males, living with their parents, never leaving their bedroom and surviving on pizzas and Redbull. Caroline Overington in the "The Australian" has said "anyone over the age of 30 who spends any time deep in some sagging sofa, console in one hand, the other down the front of their pants, imagining themselves to be a combatant in some pretend city, is lame." and that gamers "don't participate in life in any meaningful way." Michael Atkison, former South Australian Attorney-General, during his push to block an R18+ classification for video games in Australia (February 2010), referred to the games as 'terrorist simulators' and stated that his family was "more at risk from gamers than we are from the outlaw motorcycle gangs who also hate me".
With this type of media and government representation of videogames and videogame players, it is little wonder why many gamers wouldn't include videogaming as an interest on their curriculum vitae. However with $93 \%$ of households in Australia having a gaming device (Digital Australia 2014) an employer should be more surprised to see the absence of gaming on an employee resume. Furthermore, the average gamer is 32 years old; $47 \%$ of gamers are female; and the average adult gamer has been playing for 11 years and plays every day (Digital Australia 2014).

A gamer is simply a person who plays games. Whether playing FIFA 14 with 3 friends in front of the lounge-room 55" LED TV, or playing a mobile version of Words with Friends with your mother whilst you are on the bus and she's on her lunch break, you are gamers and are considered by some in the media to be, at best wasting your time, and at worst harming your health.

In "A Life Well Wasted," an internet radio show about videogames and the people who love them, Robert Ashley explores why people play games. He says that people play video games for a variety 
of different reasons. "They are fun; they are an escape from the pressures of day-to-day life. People play for social reasons, people play for a sense of accomplishment. There are opportunities for a deeper immersion than we can get through movies or television, experiencing worlds and stories that aren't attainable in the 'real world'." (Ashley 2013)

Gaming is a social hobby and 'Gamers' will discuss their favourite games in forums and chat online during gameplay. Massively Multiple Online games (MMOs) such as World of Warcraft and World of Tanks provide opportunities never experience before by humanity to play together. For example, WoW has 8 million subscribers and World of Tanks has 75 million registered players (Humphries 2013). Also gamers will gather in large numbers at conventions like The Electronic Entertainment Expo $(>50,000$ attendees) and Penny Arcade Expo (PAX) (>70,000 attendees in US alone) to share in their love of gaming.

However just like Rock n' Roll of the 1950's, Comic Books in the 1960's and Punk of the 1970's, video games and the people who play them seem to be the reason for the imminent downfall of western civilisation (Ashley 2013). But new media has always been feared. Novel reading in the 1860s was consider to be "... one of the great vices of our age. Multitudes care for nothing but light reading. The bookstores abound with works of fiction. The records of our public libraries show that there are more readers in this department than any other-perhaps more than in all the rest. The literature which finds its way into the hands of our people, as they journey by land or water, is almost invariably fictitious." (Crane 1869). In 1910 it was early motion pictures that received bad press. "85 percent of the juvenile crime which has been investigated has been found traceable either directly or indirectly to motion pictures which have shown on the screen how crimes could be committed." (criminologist cited by Münsterberg, circa 1910)

Too often we hear stories of school shootings fuelled by video game violence, teen deaths caused by 'obsessive' playing and game induced rage the cause of murder. Remember that new media has been blamed before and will be blamed in the future for societal issues.

Recently, the gaming community has become more vocal of the positive benefits of videogames to them as individuals and to broader society. Researchers have begun to realise what gamers have know for a while, that playing videogames is good for positive wellbeing (see Allahverdipour, et al 2010; Barr, Khaled, Noble \& Biddle 2006; Colwell 2007; Boyle, et al 2011; Durkin \& Barber 2002; Hull, 2009; Przybylski et al 2011; Ryan \& Deci 2008; Snodgrass, Lacy, Dengah, Fagan \& Most 2011; Wang et al 2008). Over the last five to ten years, increasing attention has been given to the possibility of games improving health and wellbeing (Desai, Krishnan- Sarin, Cavallo \& Potenza 2010). A number of more recent studies have considered a more nuanced approach to the positive and negative influences of game play and a number of significant studies have demonstrated clear benefits to individuals who spend time in game play. There is also increased concern that the potential value of videogames has not been sufficiently considered, particularly in terms of the benefits for young people at risk (Kutner \& Olson, 2008).

This paper challenges the many sensational headlines reported in the media asserting that videogames cause obesity, addiction and social isolation by presenting the latest research evidencing the positive benefits of playing games. The research evidence has been compiled from a comprehensive review of over 200 international research papers linking videogame play with positive wellbeing (Jones et al 2014, Johnson et al 2013).

\section{PLAYING GAMES MAKES YOU FAT}

The stereotypical gamer is viewed by the broader society as an adolescent overweight male with acne, eating fast food in his bedroom. However research neither supports this stereotype, nor any negative impact of playing games of physical wellbeing. Instead the gamer of today is 32 years old, equally probably to be female as male, and plays videogames with their children. True, gamers eat fast food, but no more often than the rest of the population.

Research has shown that frequency of play does not significantly relate to body mass index (weight) (Wack \& Tentelett-Dunn 2009). A team at Michigan State University in East Lansing selected a group of 482 12-year-olds and followed them for three years. Parents and children responded to six waves of surveys covering each child's internet use, how much they played video games and how often they used a mobile phone. Parents were also asked about their children's exam scores, height, weight, race and socioeconomic status, while the kids were tested in reading, mathematics, visuospatial recognition and self-esteem. The team found that while video games were used more than the internet and mobile phones, none of these activities predicted a child's weight or BMI. Instead they found that race, age and socioeconomic status were the strongest predictors (Jackson et al 2011). The researchers also found some benefits of technology use: children who used the internet more had higher test scores in reading. Those who played more video games had better visuospatial skills (Jackson et al 2011). 
Time playing videogames does not appear to replace time in physical activities. Data suggests that playing videogames is associated with increases in participation in physical sports.

\section{YOU'RE ADDICTED TO PLAYING VIDEO GAMES}

"Girl starved to death while parents raised virtual child in online game", The Guardian, UK, 6 March 2010

A three-month old South Korean girl starved to death after her parents devoted hours of time to raising a virtual girl in an online role playing game called Prius Online. The game, similar to Second Life, allows players to create virtual worlds and virtual characters. The parents of the young child would leave their infant unattended while they went to internet cafes and only return occasionally to feed her powdered milk. The baby was found to have died due to malnutrition after the parents return from a 12 hour gaming session.

"Diablo death: Teenage dies after playing video game for 40 hours without eating or sleeping", The Mirror, UK, 18 July, 2012.

An 18-year old Taiwanese boy called Chuany died after failing to eat or sleep for over 40 hours in a private room in an internet cafe. It is believed that he suffered a fatal blood clot after spending a long time seated.

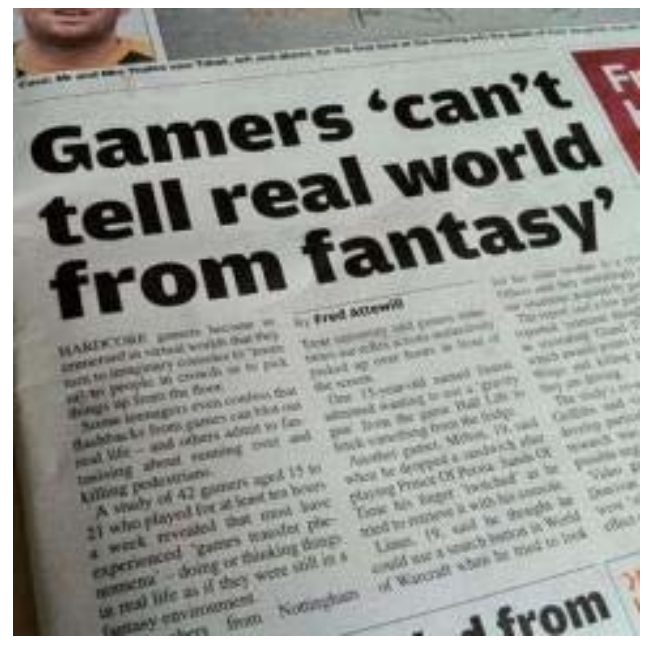

Figure 1: "Gamers can't tell real world from fantasy", The Mail, UK, 20 September 2011

Some players have become obsessed with, and addicted to, playing videogames, resulting in physical and mental harm, family breakdowns and even death, Figure 1. However are videogames the cause of this addictive behaviour or is addictive gameplay a consequence of the player's psychological wellbeing.
Although the terminology is still being debated (Lemmens et al 2011) some researchers have begun to voice concerns about addictive gaming behaviour (pathological gaming) as a legitimate behavioural disorder. The American Psychiatric Association has recently designated "Internet Gaming Disorder" as a condition requiring further study (American Psychiatric Association, 2013). Some studies of small groups of players who spend excessive amounts of time on games have shown that symptoms of addiction can arise including withdrawal, preoccupation, loss of control, and interpersonal or intrapersonal conflicts (Gentile, 2009; Grüsser, Thalemann \& Griffiths 2007), while other studies fail to support links between heavy play and negative psychosocial outcomes in nonaddicted gamers (Lemmens et al 2011, Van Rooij et al 2011). Although longitudinal research on pathological gaming is relatively scarce, three studies have evaluated the psychosocial predictors and outcomes of pathological gaming among adolescents (Lemmens et al 2011, Gentile et al 2011, Van Rooij et al 2011). These authors evaluated a large number of potential risk factors for the development of pathological gaming and concluded that time gaming as well as psychosocial factors such as impulsivity, social competence and emotional regulation all predicted the development of pathological gaming. They also found that those who became pathological gamers were more likely to show increased scores on scales measuring ADHD, anxiety, and depression.

Consistent with Gentile and colleagues' research, Lemmens and colleagues also found that lower psychosocial wellbeing was generally a precursor of pathological gaming, with diminished social competence, increased loneliness, and lower selfesteem predicting an increase in pathological gaming six months later (Lemmens et al 2011). They also found that pathological gaming was associated with even greater amounts of gaming six months later, as well as increases in selfreported physical aggression for boys.

A study by Van Rooij and colleagues (2011) of online gamers points to the persistence of pathological gaming over the course of a year, with half of a group of pathological gamers (described as having both heavy play and high self-reported addictive use) showing continued pathological use a year later. In sum, the research suggests lower psychosocial wellbeing is more likely to be a cause rather than a consequence of internet gaming addiction (Chak \& Leung 2004; Ko et al 2005), but that harm may result from play that is rated by players as addictive.

Przybylski, Weinstein, Ryan, and Rigby (2009) conducted research exploring the consequences of different styles of engagement in videogame play. The researchers were particularly interested in how 
need satisfaction in other areas of life moderated the relationship between videogame play and wellbeing. Based on a large sample $(n=1324)$ of videogame players, they established that high levels of basic psychological need satisfaction were positively related to 'harmonious' passion for videogame play (the activity is personally important, freely chosen and in harmony with other aspects of life), whereas low levels of need satisfaction were related to 'obsessive' passion for videogame play (the activity is experienced as a compulsion and conflicts with other facets of life). In turn, harmonious passion contributed to enhancing experiences of play and game enjoyment energy post-play but did not influence amount of play. In contrast, obsessive passion contributed to a disordered pattern of play including greater amounts of play, higher tension post-play, and less game enjoyment for players of some game types (Przybylski, Weinstein, Ryan \& Rigby 2009).

Game type, need satisfaction, harmonious passion and obsessive passion, game enjoyment, weekly play time, post play energy and tension, life satisfaction, psychological and physical health were measured in a study of $1,324 \quad(1,168$ male $)$ videogame players ranging in age from 18 to 43 years and recruited from a popular online community that provides a forum for discussions about videogames and Internet culture (Przybylski et al 2009b). Post-play energy and tension was measured via the energy and tension subscales of the Activation-Deactivation Adjective Checklist developed by Thayer (1986). Participants were asked to rate 10 mood adjectives relating to how they felt after playing their favoured game (Przybylski et al 2009b). Terms used reflected energy and vitality (e.g., active, energetic, vigorous), and tapped tension and anxiety (e.g., jittery, clutched up, fearful). Titles of the games enjoyed by participants were categorised into five distinct game genres with games represented including first-person shooters (316), massively multiplayer online games (309), role-playing games (284), strategy games (223), and action-adventure games (192) (Przyblski et al 2009). It was found that for those engaging with videogames harmoniously, greater hours of play were associated with greater post-play energy. In contrast, for those engaging with videogames in an obsessive manner, greater hours of play were associated with reduced post-play energy.

These studies suggests that how young people engage with videogames (harmoniously or obsessively), is more important in terms of the impact of videogame play on wellbeing than which videogames they play. Specifically, where harmonious engagement occurs players are more energised and moreover, more videogame play can lead to greater vitality.
Thus, it is a person's 'pre-existing' addictive behaviour linked with psychosocial factors that predicts addiction to videogame and length of play session. Whether the player wants to play (harmonious passion) or has to play (obsessive passion) effects their energy and satisfaction of their needs. These findings suggest that the amount of play may be less important for any positive or negative impact of videogames and instead it how videogames are played, whether they are played with others, and with whom they are played.

\section{GAMERS DON'T HAVE FRIENDS}

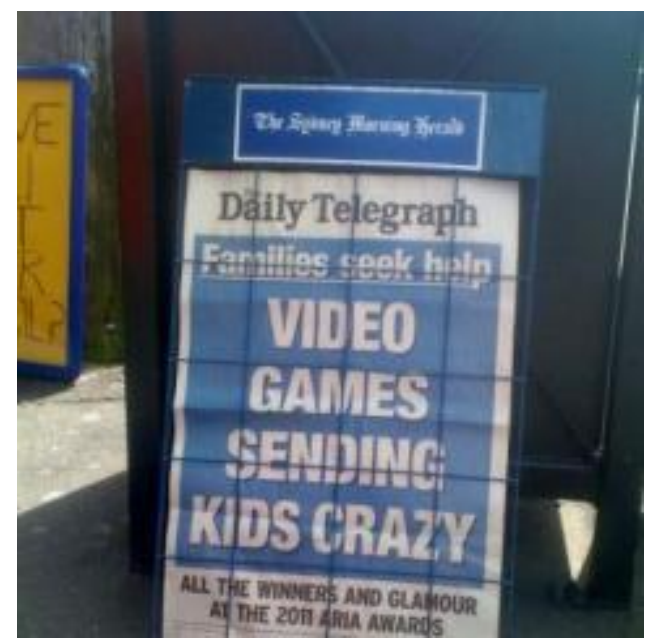

Figure 2: "Video Games Sending Kids Crazy", The Daily Telegraph, Australia, 28 November, 2011, Bruce McDougall

The media often present videogame players as loners, having low self-esteem, low social skills and preferring to play games on their own, Figure 2. However the Digital Australia national survey suggests otherwise, with over $65 \%$ of Australians playing videogames and playing games every day, and over $80 \%$ of mums and dads playing videogames (Digital Australia 2014). Videogames in themselves don't undermine social connections but rather provide unprecedented access to millions of other players around the world. Massively Multiplayer Online games (MMOs) attract many hundreds of thousands of players, for example Dofus has over 41 million players worldwide, Guild Wars (1 and 2) over 9 million, and World of Warcraft over 8 million players.

These MMOs are online "places" in which social interaction can occur and are unique in the fact that they collect and mix people (Williams et al,. 2006). World of Warcraft (WoW) is a vibrant social space for millions of players, populated with a range of social experiences ranging from ephemeral impersonal groups to sustained and deep relationships that extend offline. Games such as WoW include structure and rule sets impacting on 
what kinds of people play, what they do, and how and why they interact with one another. As part of gameplay social organisations are created with the design encouraging the formation of persistent player associations (Taylor, 2003).

Genres of videogames other than MMOs also offer opportunities for socialising with other players. For example first-person-shooters and sport games almost always include online multiplayer modes that allow for both competitive and cooperative play. Similar modes are also sometimes included in action games, platforming games, puzzle games and other genres. McGonigal reports that videogame players are part of something bigger than themselves (McGonigal, 2011). Reporting that in the final campaign in Halo 3 when gamers must protect the Earth from alien attack, players collective completed over 10 billion kills (achieved April 2009), which is 12,000 kills a minute. Although there is no real value in killing an alien in Halo 3 , McGonigal suggests that this doesn't mean they don't have meaning. Meaning is significant not just to ourselves or friends and family, but rather to a much larger group such as the whole Human race. Seligman suggests that the larger the group you can attach yourself to the more meaning you can derive (Seligman, 1998, p287). Connecting with millions of videogame players across the world against a common in-game attack is bigger than any one player and this can derive meaning and wellbeing. In the eight years of Halo 3 play to April 2012, players compiled more than 123 billion hours of gaming, or more than 85 million days, achieving more than 136 billion kills and earning over 79 billion medals (in-game awards based on a player's actions during a typical multiplayer match) for their gaming.

When WoW players work together in guilds they often participate in highly structured organizational experiences working towards common goals. Players in formally structured guilds tend to have a more social experience than others. Playing WoW is thus like a team sport, which has its own rules, literal boundaries, and social norms (Williams et al., 2006). There are however self-initiated tactics, team strategies, styles, and goals that make the play space a stage for socialization, organization, and networks.

MMO gamers under the age of 18 have reported that friendships they form online are comparable or better than their real-life friendships (Yee, 2006). WoW players report creating social capital through online gameplay with players using the game to extend real life relationships, meet new people and form relationships of varying strengths (Williams, Ducheneaut, Xiong, Zhang, Yee, \& Nickell, 2006). As Cole \& Griffiths (2007) found in their study of 912 self-selected MMOs players from 45 countries, the social interactions in online gaming form a considerable element in the enjoyment of playing, with three quarters of both male and female players having made good friends within online games (Cole \& Griffiths 2007).

It can be argued that online communication is being used to enhance both the quantity and quality of communication between friends, leading to greater closeness and intimacy (Valkenburg and Peter 2011). Playing online with friends who are also friends in real life is healthy, as interactions help regulate game play (Snodgrass, Lacy, Dengal, Fagan, 2011). Playing with real life friends also allows players to transfer positive gaming experiences into real life. However playing with real friends makes it harder to immerse, impacting on some of the stress reduction benefits although also potentially reducing the risk of problematic play and addiction. Playing with real life friends also allows players of WoW to share their experiences of success and achievement to bolster and repair their feelings of worth and esteem as players. Players are then able to transfer in-game accomplishments and status to their real-life networks of friends and family. Playing WoW in this way creates cognitive and social bridges between on- and off-line worlds providing more objective perspective on MMO use and allowing better selfregulation. Therefore, playing with friends has the potential to affect levels of problematic play by mediating immersion and enhancing real-life relationships increasing social and psychological resilience (Snodgrass, Lacy, Dengal, Fagan, 2011, Colwell, 2007; Hull, 2009; Trepte, Reinecke, \& Juechems, 2012; Wack \& Tantleff-Dunn, 2009).

Positive relationships within online videogames provide opportunities for social and emotional support. Two fifths of study participants said they would discuss sensitive issues with their online gaming friends that they would not discuss with their real life friends, and with female players more likely to do this (Cole \& Griffiths, 2007). Two fifths of participants had met their online friends in reallife, suggesting that online videogaming is a social activity and facilitates social connections. A third of participants were attracted to another player (26\% males compared to $42 \%$ females) suggesting that MMOs offer a safe environment for players to become emotionally involved with others. It would appear that videogames allow players to express themselves in ways they may not feel comfortable doing in real life because of their appearance, gender, sexuality, and/or age.

Online social videogames such as Words with Friends (similar to Scrabble) are encouraging families and friends to keep in touch. These games alert players that it is their turn and players can chat and/or leave messages. In fact the game can be an excuse and mechanism for conversations to occur, with mothers and daughters discussing 
every day events and exchanging messages of affection. Playing these asynchronous games where both players don't need to be online at the same time but can play their turn when convenient, encourages players to continue to exchange and regularly (McGonigal, 2011). This 'stickiness' (the ability of the game to keep the players playing) draws together the players to build and maintain positive relationships.

Videogames can eliminate loneliness. Even when friends and family are separated by time and distance, videogames can allow players to interact, share and be social (Pwn or Die Blog 12 ways, 2009). Meeting online to play together in a game, can provide strong social and emotional ties, and more meaning for society both within and beyond the game.

\section{PLAYING GAMES MAKES YOU VIOLENT}

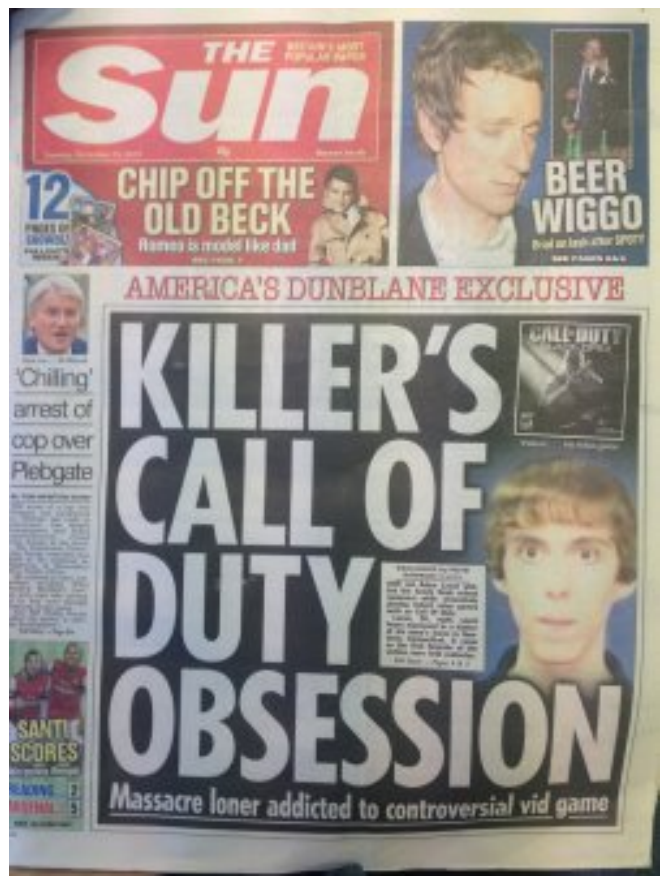

Figure 3: "Killer's Call of Duty Obsession" - The Sun, UK, 18 Dec 2012, Damien McFerran

Traditionally, much of the research on videogames has focused on the negative effects of playing, Figure 3. However we argue that research reporting the effects of violent games on aggression has room for improvement. The existing body of research has been criticised for concerns about publication bias and an emphasis on the use of laboratory measures of aggression that exaggerate relationships between videogame violence and aggression and do not accurately predict real life behaviour (Boyle, Connolly \& Hainey 2011; Ferguson, 2007; Kutner \& Olson 2008; Sherry 2004, 2007).
More recent research includes studies focusing on longitudinal measures that attempt to demonstrate causal relationships between violent videogames and aggression. Many of these studies rely on selfreported measures of aggressive feelings or attitudes (Lemmens et al 2011; Möller \& Krahé 2009; Anderson et al 2010; Shibuya, Sakamoto, Ihori \& Yukawa, 2008), while other studies include self-reported counts of aggressive behaviours (Shibuya et al 2008; Bucolo 2011) or combined teacher and peer ratings (Gentile \& Gentile 2008). While some of those studies do report associations between earlier violent videogame play and later self-reported aggression (Anderson et al 2010; Bucolo 2011;Möller \& Krahé 2009) or combined peer-and teacher-reported aggression (Gentile \& Gentile 2008), others do not support long-term direct effects of violent videogames on selfreported physical aggression (Lemmens et al 2011; Shibuya et al 2008).

Violence is not an important factor in contributing to game enjoyment. Players play violent games for the same reasons they play other games, such as enjoyment of the challenge and the freedom to act in a virtual world (Przybylski, Ryan \& Rigby 2009).

There are many creative, social and emotional benefits from playing videogames, including violent games (Kutner \& Olson 2008). Focusing on violent videogames as a precursor to aggression may cause parents, social activists and public-policy makers to ignore the much more powerful and significant causes of violence amongst young people that have already been well established, including a range of social, behavioural, economic, biological and mental-health factors (Kutner \& Olson 2008; Ferguson et al 2013).

\section{PLAYING GAMES MAKES YOU STRESSED OR DEPRESSED}

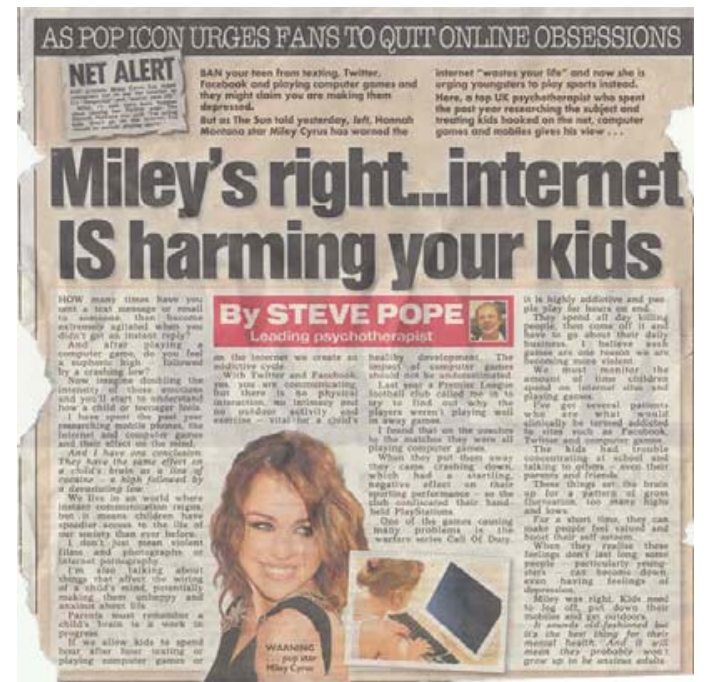

Figure 4: "Gaming can cause depression" - The Sun, UK, 18 March 2010, Steve Pope (psychotherapist) 
Miley Cyrus urges youngsters not to use the internet as it's "dangerous" and "wastes your life". Miley, 17, said she's been happier since closing her Twitter page. Things like texting, Twitter, Facebook and videogames can apparently cause teenagers to become depressed, and should be 'banned'. In this article, Figure 4, Steve Pope talks about working with an English Premier League Football club to find out why the players weren't playing well in away games. He attributed their poor form on playing Call of Duty when travelling on coaches to away matches. He says "They spend all day killing people, then come off it and have to go about their daily business. I believe such games are one reason we are becoming more violent"

It may be easy for the media to report that social technologies and in particular videogames are a cause of negative emotions, stress and depression. However emerging research suggests that moderate game play instead contributes to positive emotions (Allahverdipour et al., 2010; Kutner \& Olson, 2008; Ryan, Rigby, \& Przybylski, 2006; Przybylski, Ryan, \& Rigby, 2009: Wang et al., 2008) and emotional stability (Przybylski et al., 2011). Positive mental wellbeing has also been associated with game play as a means of relaxation and stress reduction (Russoniello, O'Brien, \& Parks, 2009; Snodgrass, Lacy, Dengah, Fagan, \& Most, 2011; Wack \& Tantleff-Dunn, 2009).

The amount of game play is a moderating factor on the player's personal wellbeing. Durkin and Barber's (2002) examination of the relationship between game play and several measures of adjustment for 1304 high school students, found that videogame play was unlikely to be harmful and instead was often associated with positive outcomes. There were advantages for those adolescents who occasionally played videogames (low use) and those who played daily (high use) compared to the young people who reported that they never played games (never) (Durkin \& Barber, 2002). Specifically, depressed mood was significantly lower in the 'low' use group compared to the 'never' and 'high' groups who reported similar outcomes. Self-esteem was also higher in the 'low' use group with self-concept regarded higher by players than non players, with 'high' use players scoring the highest in this domain. Both groups of players also reported higher levels of family closeness and less risky friendship networks than non-players, with attachment to school also higher in these two videogame play groups.

Allahverdipour et al. (2010) found that middleschool students with moderate amounts of gameplay report better mental health compared to non-gamers and excessive gamers. Gamers spent an average of 6.3 hours per week playing video games with $47 \%$ reporting that they had played one or more intensely violent games including: Dead or Alive, Def Jam, Doom, Driver, Mortal Kombat, Grand Theft Auto, Resident Evil, and Prince of Persia. Moreover, $92 \%$ of boys and $96 \%$ of girls played video games although boys typically played games for greater duration than girls. However, it is the amount of gameplay that appears significant, with moderate gaming among young men providing a healthy source of socialization, relaxation, and coping (Wack \& Tantleff-Dunn, 2009). Defining 'non-gamers' as those who did not play at all, 'low' 1-6 hours per week, 'moderate' 7-10 hours per week, and 'excessive' as more than 10 hours per week, Allahverdipour et al. (2010) found a curvilinear relationship between videogame playing and mental health outcomes with 'moderate' gamers faring best. Although 'excessive' gamers showed mild increases in problematic behaviours (such as somatic symptoms; anxiety and insomnia; social dysfunction, and general mental health status), it was 'non-gamers' who indicated the poorest outcomes on these constructs. Nongaming has been found to put boys, in particular, at greater risk for problems. This effect for nongamers has also been reported by others who found gaming positively contributed to creative, social, and emotional benefits (Kutner \& Olson, 2008).

There is concern that the potential benefits of videogames (including some games with violent content) have not received enough attention. Kutner and Olson, co-directors of the Harvard Medical School Center for Mental Health and Media, recently found that boys who did not play any videogames during a typical week had a high risk of emotional disturbance. Boys playing videogames are using these games for emotional regulation, to help them relax, to forget problems, or to feel less lonely (Kutner \& Olson, 2008). While the survey did find correlations between Maturerated violent gameplay and some common childhood problems such as aggressive behaviours or school problems this risk was for both boys and girls. However results did not show causality and most children who played violent games did not have problems. In fact many of boys describe using violent videogames to manage their emotions and to deal with anger, frustration and stress (Keyes, 2002; Kutner \& Olson, 2008).

Children use videogames as a means of mood alteration or 'letting off steam', following problems at school, or with friends or with parents (Colwell, 2007). Feelings of anger, guilt, or frustration are dissipated after some time spent in game play. Furthermore children have an understanding of the mood altering benefits of their videogame play and explicitly make choices to engage with videogames to manage their emotions. 


\section{CONCLUSIONS}

Arguably the first successful videogame, and which led to the popularisation of the medium, was Pong, developed and released by Bushnell and Dabney in 1972. Videogames have come a long way in 40 years from the early 'electronic tennis' to the deeply emotive narrative of 'The Last of Us' and the immense online worlds of 'Eve Online'. Similarly it is time for the media to recognise that videogames have grown up and are able to sophistically explore complex and sensitive subject matters such as 'Papo \& Yo' a fantasy adventure videogame involving a young Brazilian boy Quico and his abusive, alcoholic father.

Gamers are not a minority, nor atypical of society. Instead most of 'us' play games, and play games every day. Whether you play causal games such as Words with Friends or enjoy a World of Warcraft party, as a species, humans play about 3 billion hours a week (about 125 million days worth, or 342,239 years). By the time they are 21, most children will have played about 10,000 hours worth of video games, which is about the same amount of time they will spend in school. Humanity wants to play games and games are good for us. Research is showing that videogames can help fight depression, improve brain function and stimulate creativity. Videogame players report higher levels of family closeness, less risky friendship networks and better attachment to school than non-players (Durkin \& Barber 2002). Moderate videogame play among young men can provide a healthy source of socialisation, relaxation, and coping (Wack \& Tantleff-Dunn 2009), and videogaming among college-aged men has been seen to provide a healthy source of socialisation, relaxation, and combating stress (Wack \& Tentelett-Dunn 2009, Snodgrass, Lacy, Dengal \& Fagan 2011; Snodgrass, Lacy, Dengah, Fagan \& Most 2011; Snodgrass et al 2012). Moderate videogame play can contribute to positive emotions (Allahverdipour, Bazargan, Farhadinasab \& Moeini 2010; Kutner \& Olson 2008; Ryan, Rigby \& Przybylski 2006; Przybylski, Ryan \& Rigby 2009; Wang, Khoo, Liu \& Divaharan 2008), and can contribute to emotional stability (Przybylski, Weinstein, Murrayama, Lynch \& Ryan 2011). Depressed mood has been found to be significantly lower in the moderate players of videogames compared to those who 'never' play videogames and those who play videogames to excess (Durkin \& Barber 2002), and non-gaming has been found to put boys, in particular, at greater risk for problems. Boys who did not play any videogames during a typical week had a higher risk of emotional disturbance compared to children who were using games for emotional regulation - to help them relax, to forget problems, or to feel less lonely (Kutner \& Olson 2008).
Children play games as a means of mood alteration or 'letting off steam' in response to problems with friends or parents, and it appears that children and adolescents deliberately choose to play videogames in the knowledge that they will feel better as a result (Colwell 2007).

Videogames have been found to be an effective play therapy tool. Children can be helped to change their views of themselves and the world around through metaphors in games, e.g., 'the force' in Lego Star Wars, gaining 'attributes' in SSX-3 (snowboarding), and conquering 'quests' in RuneScape (Hull 2009). Self-esteem was higher in the moderate videogame players, while selfconcept was higher amongst players compared to non-players (Durkin \& Barber 2002), and videogame play may allow players to express themselves in ways they may not feel comfortable doing in real life because of their appearance, gender, sexuality, and/or age (Coles \& Griffith 2007).

The 'average' gamer aged 32 has grown up with videogames; our children intuitively know how to use videogames; and the elderly are adopting videogames to maintain physical and mental wellbeing and social connections. The potential benefits of videogames to the individual and to society are yet to be fully realised. However already videogames are helping many gamers to flourish in life. Gamer designers and gamers must take responsibility for the quality and use of videogames, and the media must welcome the greatest opportunity ever experience by humanity to play together, and to play well together.

\section{REFERENCES}

Allahverdipour, H., Bazargan, M., Farhadinasab, A., \& Moeini, B. (2010). Correlates of video games playing among adolescent in an Islamic country. BMC Public Health, 10, 286. Retrieved from $\quad$ http://www.biomedcentral.com/1471$\underline{2458 / 10 / 286}$

American Psychiatric Association: Diagnostic and Statistical Manual of Mental Disorders, Fifth Edition. (2013), American Psychiatric Association, Arlington, VA, accessed from <dsm.psychiatryonline.org>.

Anderson, C A, Shibuya, A, Ihori, N, Swing, E L, Bushman, B J, Sakamoto, A \& Saleem, M (2010), 'Violent Video Game Effects on Aggression, Empathy, and Prosocial Behavior in Eastern and Western Countries: A Meta-Analytic Review,' Psychological Bulletin, vol. 136(2), pp. 151-173.

Ashley, R. (2013), Gamer - The Stereotype, http://gamerstereotype.wordpress.com/ 
Barr, P., Khaled, R., Noble J., \& Biddle, R, (2006). Feeling Strangely Fine: The Well-being Economy in Popular Games. Proceedings of the First International Conference on Persuasive Technology for Human Well-being, 60-71, Springer-Verlag Berlin, Heidelberg.

Boyle, E.A., Connolly, T.M., \& Hainey, T. (2011). The role of psychology in understanding the impact of computer games. Entertainment Computing, 2(2), 69-74.

Digital Australia (2014). National research prepared by Bond University for the Interactive Games \& Entertainment Association. School of Communication and Media, Faculty of Humanities and Social Sciences, Bond University. http://www.igea.net/2013/10/digitalaustralia-2014/

Bucolo, D (2011), Violent videogame exposure and physical aggression in adolescence: Tests of the general aggression model, ProQuest Information \& Learning, US.

Chak, K, \& Leung, L (2004), 'Shyness and locus of control as predictors of Internet addiction and Internet use,' Cyberpsychology and Behavior, vol. 7, pp. 559-570.

Cole, H., \& Griffiths, M. (2007). Social interactions in massively multiplayer online role-playing gamers. Cyberpsychology and Behavior, 10(4), 575- 583.

Colwell J. (2007). Needs met through computer game play among adolescents. Personality \& Individual Differences, 43, 2072-82.

Crane, J.T., (1869), Novels and Novel-Reading, by Rev. J. T. Crane from Popular Amusements. Cincinnati: Walden \& Stowe, 1869; pp. 121-152

Desai, R. A., Krishnan-Sarin, S., Cavallo, D. \& Potenza, M. N. (2010). Video-gaming among high school students: Health correlates, gender differences, and problematic gaming. Pediatics, 126 (6), e 1414.

Digital Australia (2014). Interactive Games \& Entertainment Association, www.igea.net

Durkin, K. \& Barber, B. (2002). Not so doomed: Computer game play and positive adolescent development. Journal of Applied Developmental Psychology, 23, 373-392.

Ferguson, C. J. (2007). The good, the bad and the ugly: A meta-analytic review of positive and negative effects of violent video games. Psychiatric Quarterly 78, 309-316.

Ferguson, C J, Garza, A, Jerabeck, J, Ramos, R, \& Galindo, M (2013), 'Not worth the fuss after all? Cross-sectional and prospective data on violent videogame influences on aggression, visuospatial cognition and mathematics ability in a sample of youth,' Journal of youth and adolescence, vol. 42(1), pp. 109-22. doi:10.1007/s10964-012-9803-6.

Gentile, D A (2009), 'Pathological videogame use among youth 8 to 18 : A national study,' Psychological Science, vol. 20, pp. 594-602.

Grüsser, S M, Thalemann, R \& Griffiths, M D (2007), 'Excessive computer game playing: Evidence for addiction and aggression?' CyberPsychology and Behavior, vol. 10, pp. 290292.

Hull, K. (2009). Computer/video games as a play therapy tool in reducing emotional disturbances in children. (Doctoral dissertation). UMI Number: 3380362

Humphries, M. (2013), http://www.geek.com/ games/world-of-warcraft-peaked-at-12-millionplayers-world-of-tanks-just-passed-75-million1579885/

Jackson L.A., Eye A., Fitzgerald H.E., Witt E.A., Zhao Y. (2011). Internet use, videogame playing and cell phone use as predictors of children's body mass index (BMI), body weight, academic performance, and social and overall self-esteem, Computers and Human Behavior, vol 27, p 599604

Johnson, D, Jones, C, Scholes, L \& Carras, M (2013) Videogames and Wellbeing, Young and Well Cooperative Research Centre, Melbourne.

Jones C.M., Scholes L., Johnson D., Katsikitis M. \& Carras M.C. (2014) Gaming well: Links between videogames and flourishing mental health, Frontiers in Developmental Psychology

Keyes, C.L.M. (2002). The mental health continuum: From languishing to flourishing in life. Journal of Health and Social Behavior, 43, 207222.

Ko, C, Yen, C, Yen, C, Yen, J, Chen, C \& Chen, S (2005), 'Screening for Internet addiction: An empirical research on cut-off points for the Chen Internet Addiction Scale,' The Kaohsiung Journal of Medical Sciences, vol. 21, pp. 545-551.

Kutner L, Olson, C., K. (2008). Grand theft childhood: The surprising truth about violent video games and what parents can do. New York: Simon \& Schuster.

Lemmens, J, Valkenburg, P \& Peter, J (2011), 'Psychosocial causes and consequences of pathological gaming,' Computers in Human Behavior, vol. 27, pp. 144-152.

McGonigal, J. (2011). Reality is broken: Why games make us better and how they can change the world. Sydney: Random House. 
Möller, I \& Krahé, B (2009), 'Exposure to violent videogames and aggression in German adolescents: A longitudinal analysis,' Aggressive Behavior, vol. 35(1), pp. 75-89.

Overington C. (2010), Hell's bells, these boys need to act their age, The Australian, 11 February

Przybylski, A. K., Ryan, R. M., \& Rigby, C. S. (2009). The motivating role of violence in video games. Personality and Social Psychology Bulletin, 35(2), 243-259.

Przybylski, A K, Weinstein, N, Ryan, R M \& Rigby, C S (2009), 'Having to versus wanting to play: Background and consequences of harmonious versus obsessive engagement in videogames,' CyberPsychology \& Behavior, vol. 12(5), pp. 485-492, doi:10.1089/cpb.2009.0083.

Przybylski, A.K., Weinstein, N., Murrayama, K., Lynch, M.f., \& Ryan, R.M. (2011) The ideal self at play: The appeal of video games that let you be all you can be. Pscyhological Science, 23, 69-76.

Pwn or Die Blog. (2009). 12 Ways Video Games Actually Benefit Real Life [Web log post]. Last modified May 12, 2009. Retrieved from http://www./pwnordie.com/blog/posts/15739.

Russoniello, C. V. O' Brien, K. \& Parks, J. M. (2009). The effectiveness of casual video games in improving mood and decreasing stress. Journal of CyberTherapy and Rehabilitation, 2(1), 53-66.

Ryan, R.M. \& Deci, E.L. (2008). From ego depletion to vitality: Theory and findings concerning the facilitation of energy available to the self. Social and Personality Psychology Compass, 2(2), 702-717.

Ryan, R.M. Rigby, C.S. \& Przybylski, A. (2006). The motivational pull of video games: A selfdetermination theory approach, Motiv Emotion, 30, 347-363

Seligman, M. (1998). Learned Optimism. New York: Pocket Books.

Sherry, J. (2004). Flow and media enjoyment. Communication Theory, 14(4), 328-347.

Snodgrass, J., Lacy, M., Dengah, F., Fagan, J. (2011). Enhancing one life rather than living two: Playing MMO's with offline friends. Computers in Human Behaviour, 27(3), 1211-1222.
Snodgrass, J., Lacy, M., Dengah, F., Fagan, J., Most, D. (2011). Magical Flight and Monstrous Stress: Technologies of Absorption and Mental Wellness in Azeroth, Culture, Medicine, and Psychiatry, 35(1), 26-62.

Snodgrass, J., Dengah, F., Lacy, M., Fagan, J., Most, D., Blank, M.,Wintersteen, B. (2012). Restorative Magical Adventure or Warcrack? Motivated MMO Play and the Pleasures and Perils of Online Experience, Games and Culture , 7(1), 13-28.

Trepte, S., Reinecke, L. \& Juechens, K. (2012) The social side of gaming: How playing online computer games creates online and offline social support. Computers in Human Behavior, 28, 832-839

Valkenburg, P. M., \& Peter, J. (2011). Online communication among adolescents: An integrated model of its attraction, opportunities, and risks. Journal of Adolescent Health, 48, 121-127.

Van Rooij, AJ, Schoenmakers, TM, Vermulst, AA, van den Eijnden, RJJM \& van de Mheen, D (2011), 'Online videogame addiction: Identification of addicted adolescent gamers.', Addiction, vol. 106, no. 1, pp. 205-212.

Wack, E., \& Tantleff-Dunn, S. (2009). Relationships between electronic game play, obesity, and psychosocial functioning in young men. Cyberpsychology \& Behavior, 12(2), 241-2444.

Wang,C.K., Khoo, A., Liu, W.C. \& Divaharan, S. (2008). Passion and intrinsic motivation in digital gaming. CyberPscyhology \& Behaviour, 11(1), 39-45.

Williams, D., Ducheneaut, N., Xiong, L., Zhang, Y., Yee, N., \& Nickell, E. (2006). From tree house to barracks: The social life of guilds in World of Warcraft. Games and Culture, 1, 338-361.

Words with Friends. (2013). Retrieved from http://www.wordswithfriends.com/

Yee, N. (2006). Motivations for playing online games. Cyberpsychology and Behaviour, 9(6), 772-775. 